\title{
Linkages among U.S. Treasury Bond Yields, Commodity Futures and Stock Market Implied Volatility: New Nonparametric Evidence
}

- Vychytilová Jana

\begin{abstract}
This paper aims to explore specific cross-asset market correlations over the past fifteen- yearperiod- from January 04, 1999 till April 01, 2015, and within four sub-phases covering both the crisis and the non-crisis periods. On the basis of multivariate statistical methods, we focus on investigating relations between selected well-known market indices- U.S. treasury bond yields- the 30 -year treasury yield index (TYX) and the 10-year treasury yield (TNX); commodity futuresthe TR/J CRB; and implied volatility of S\&P 500 index- the VIX. We estimate relative logarithmic returns by using monthly close prices adjusted for dividends and splits and run normality and correlation analyses. This paper indicates that the TR/J CRB can be adequately modeled by a normal distribution, whereas the rest of benchmarks do not come from a normal distribution. This paper, inter alia, points out some evidence of a statistically significant negative relationship between bond yields and the VIX in the past fifteen years and a statistically significant negative linkage between the TR/J CRB and the VIX since 2009. In rather general terms, this paper thereafter supports the a priori idea- financial markets are interconnected. Such knowledge can be beneficial for building and testing accurate financial market models, and particularly for the understanding and recognizing market cycles.
\end{abstract}

Keywords: return-volatility relation, stocks, commodities, VIX, TYX

JEL Classification: F36, F30, G15

\section{INTRODUCTION}

The importance of the financial markets, institutions and instruments has grown markedly during the last five decades. Nowadays, also with fewer and fewer barriers to international trade and financial flows, and with communications technology directly linking each major financial centre, the dimensions of international finance and financial markets is becoming more and more unique. At the same time, a major part of the financial industry has been effectively globalized, linking borrowers and lenders, issuers and investors, risks and risk takers around the world. Even though most if not all finance must be viewed at the international level. Movements in exchange rates of currencies, bond yields, as well as movements in commodity and stock returns can have profound effect on sales, costs, profits asset and liability values, and individual well-being of multinational and transnational companies (TNCs, MNCs) but also of many medium-sized and small firms as a result of globalization and integration of world financial markets. (Choi, 2003, Levi, 2005; Pilbeam, 2005).

Financial activity is extremely important in present-day in financial markets and complete knowledge of statistical properties of asset return dynamics is essential for fundamental and ap- 
plied reason and one of the reason is that such knowledge is crucial for the building and testing a statistical model of a financial market (Mantegna \& Stanley, 2000).

This paper deals with the issue of cross-asset-market relations in the context of a coherent financial framework, while the main aim of it is to investigate the linkages between the U.S. treasury bond yields, commodity futures and equity market implied volatility during the different phases including crisis and non-crisis periods.

\section{THEORETICAL BACKGROUND}

Mantegna and Stanley (2000) pointed out financial markets are remarkably well-defined complex systems, which are continuously monitored - down to time scales of seconds and therefore are so attractive for researchers interested in developing a deeper understanding of modeling of complex systems. They highlighted the key year 1973, when currencies began to be treaded in financial markets and their values started to be determined by the foreign exchange market all over the world. During the same year, Black and Scholes published the first paper presenting a rational option-pricing formula and since that time the volume of foreign exchange trading has been growing at an impressive rate. Moreover, impressive growth has taken place in the field of derivative products. A second revolution started in the 1980s when electronic trading was adapted to the foreign exchange market and prices at which traders are willing to buy (bid quotes) or sell (ask quotes) was put in place at about the same time and electronic trading become widespread and led to enormous expansion of financial markets connected with high-frequency data. (Mantegna \& Stanley, 2000; Black \& Scholes, 1973)

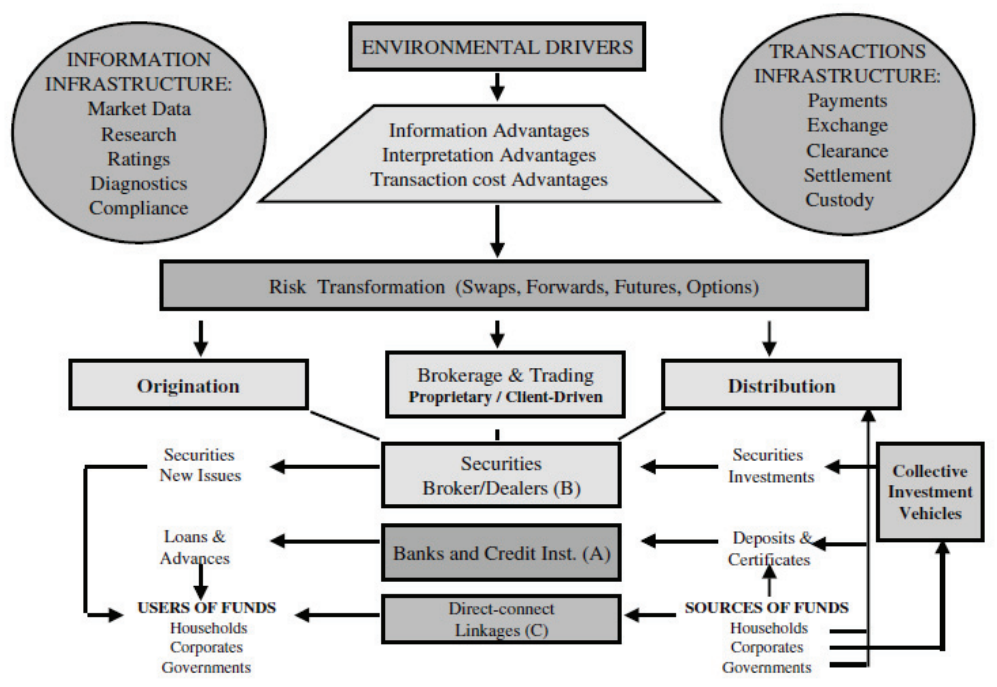

Fig. 1 - Intermediation Dynamics. Source: Choi (2003).

Choi (2003) stated that the central component of any model of a modern financial system is the nature of the conduits through which the financial assets of the ultimate savers flow through to 
the liabilities of the ultimate users of finance, both within and between national economies and added that thinking about financial contracting and the role of financial institutions and markets is important topic. Fig.1 by Choi (2003) illustrates that ultimate users of funds comprise the same three segments of the economy - consumer sector, the business sector and the government sector and shows the financial process (flow-of-funds) among the different sectors of economy in terms of underlying environmental and regulatory determinants as well as the generic advantages profit from: 1) Fully intermediated financial flows, 2) investment banking and securitized intermediation, and 3) Direct-connect mechanism between ultimate borrowers and lenders.

\subsection{Long-term Global Market Correlations}

Several researches (e.g. Alaoui et. al, 2015; Chien et.al., 2015; Darbar \& Deb, 1999; Dorodnykh, 2014; Elton \& Gruber, 1995; Engsted \& Tanggaard, 2002; Karolyi, 1995; Mantegna \& Stanley, 2000; Roll, 1989) focused on investigating financial market contagion and integration. Research of Darbar and Deb (1999) showed evidence of significant linkages across asset markets in United States between years 1987 and 1993 and proposed close connection between the commodity and currency markets and between stock and bond markets. On the other hand they stated, that there was little evidence of linkages between the bond and commodity markets. Moreover, they discussed these relations separately (following Karolyi, 1995), also in relation to international crash of equity markets in mid-October 1987. According to this disastrous event, it provoked many scientific papers - theoretical or empirical on market volatility, international market links, and market structure to be written (Roll, 1989). Mantegna and Stanley (2000) stated that the presence of cross-correlations between stock market returns has long been known, plays an important role in the theory of selecting most efficient portfolio and investigating, detecting and determining the specific properties as well as economic factors affecting the dynamics of asset prices in financial markets is challenging in economics research. (Elton \& Gruber, 1995).

Engsted and Tanggaard (2002) analyzed the relationship between expected stock and bond returns and expected inflation at short and long horizons by using a vector-autoregressive model (VAR approach) and investigated that the relationship between expected returns and inflation was positive but quite weak. Goetzmann, et. al., (2005) examined the correlation structure of the major world equity markets from 1850 to 2005 and found out that global market correlations vary considerably through time and are highest during periods of economic and financial integration such as the late 19th century, the Great Depression and the late 20th century and concluded that the time-series of average correlations show a pattern consistent with the " $U$ " shaped hypothesis about the globalization at the two ends of the 20th century and periods of globalization have both benefits and drawbacks for investors, while diversification relies increasingly on investment in emerging markets. Silvennoinen and Thorp (2013) estimated sudden and gradual changes in correlation between stocks, bonds and commodity futures returns by using double smooth transition conditional correlation (DSTCC-GARCH) models and observed that most correlations begin the 1990s near zero but closer integration emerged around the early 2000 s and reached peaks during the global financial crisis. Moreover, they proposed higher VIX increases commodity returns correlation with equity returns, indicating closer integration. 
Spierdijk and Umar (2015) focused on analyzing the U.S. stock, bonds and T-bills in relation to inflation during the years 1983-2012 and provided only partial confirmation of the hypothesis, that during the post-180 period, the returns of cyclical stocks exhibit a more positive long-run relation with inflation than the returns of non-cyclical stocks and added that both cyclical and non-cyclical industries had virtually no hedging ability until the fall of Lehman Brothers in September 2008. Moreover, they found out only short positions in long-term bond indices including treasury bonds with maturities of 10 years and longer had some long-run inflation hedging capacity. According to stock return-inflation relation, it has been recently investigated by several researchers, e.g., Katzur et. al. (2013), Hong et. al. (2013) or Lee (2010). Lee (2010) highlighted two regimes "pre-war regime with positive relation" and "post-war regime with negative stockinflation relation" by using VAR identification method. Hong et. al. (2013) added, that the negative relation is particularly strong in recession periods, indicating that the relation is sensitive to business cycle, which is at odds with the inflation illusion hypothesis anticipating inflation being related to negative returns. Katzur et. al. (2013) discussed a widespread economic assumption, that an asset is a good hedge against inflation if the Fisher hypothesis holds, nominal asset returns move in parallel with expected inflation. They showed that the economic significance of the influence of expected inflation on stock returns can be substantial, despite a lack of traditional evidence against the Fisher hypothesis.

Ong (2015) focused on information theory to examine dynamic relationships between stock returns, volatility and trading volumes for S\&P500 stocks as an alternative to traditional Granger causality test when dealing with nonlinear relationships and highlighted the dominant role played by trading volumes in all these relationships. Xiao et. al., (2015) found out the cross-correlations between different stock markets may hint et log-periodic oscillations by using de-trended crosscorrelation analysis which may be helpful to evaluate financial state in a global way.

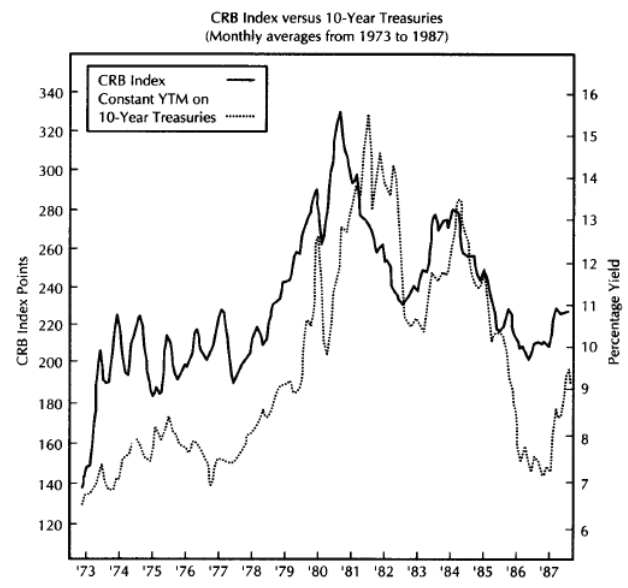

Fig. 2 - A demonstration of the positive correlation between the TR/J CRB index and 10-year Treasury yields from 1973 to 1987. Source: Murphy (2004). 
Finally, it should be added that Murphy (2004) stated that, in general, commodity prices move opposite to bond prices. This statement indicate that commodity prices and bond yields move in the same direction (see Fig. 2 illustrating a demonstration of the positive linkage between the commodity TR/J CRB index and the bond yields-10-year Treasury (TNX). He also added, inter alia, that bond prices normally trend in the same direction as stock prices. His conclusions were supported, for example, by those of Katsanos (2008).

\section{MATERIALS AND METHODS}

\section{Assumptions and hypotheses}

We set two hypotheses in our research, based on a priori basic intermarket assumption about globally and domestic interconnection of financial markets (Murphy, 2004; Katsanos, 2009).

H1. U.S.treasury bond yields (TYX or TNX) and commodity futures (TR/J CRB) were positively correlated during the analyzed period.

H2. U.S. treasury bond yields (TYX, TNX) and equity market volatility (VIX) were negatively correlated during the analyzed period.

\section{Time series and methodology}

The data consists of (January 041999 through April 01 2015) of monthly prices for four wellknown indices of financial assets in the U.S.- the Thomson Reuters/Jefferies commodity index (TR/J CRB) that is made up of 19 commodities, the 30-year treasury yield index (TYX), the 10 -year treasury yield (TNX), and the implied volatility of S\&P 500 index options (VIX); and has been obtained from Yahoo Finance.com and Investing.com. Then we define monthly returns as logarithmic differences of close prices (multiplied by 100). The full period, consequently, consists of 780 observations. We also consider four equity market sub-periods (see Fig. 3), first from January 041999 to December 312002 (Phase1), second from January 012003 to December 31 2006 (Phase2), third from January 012007 to December 312008 (Phase3), and fourth from January 012009 to April 012015 (Phase4); to separate returns influenced due to the global financial crisis 2007/2008 and earlier between 1999-2002 during the Argentine great depression followed by September 11 attacks. In addition, we use data on monthly basis those are more appropriate to understate the direction of movement than i.e. the daily data due to higher volatility (see e.g., Roll, 1989). 


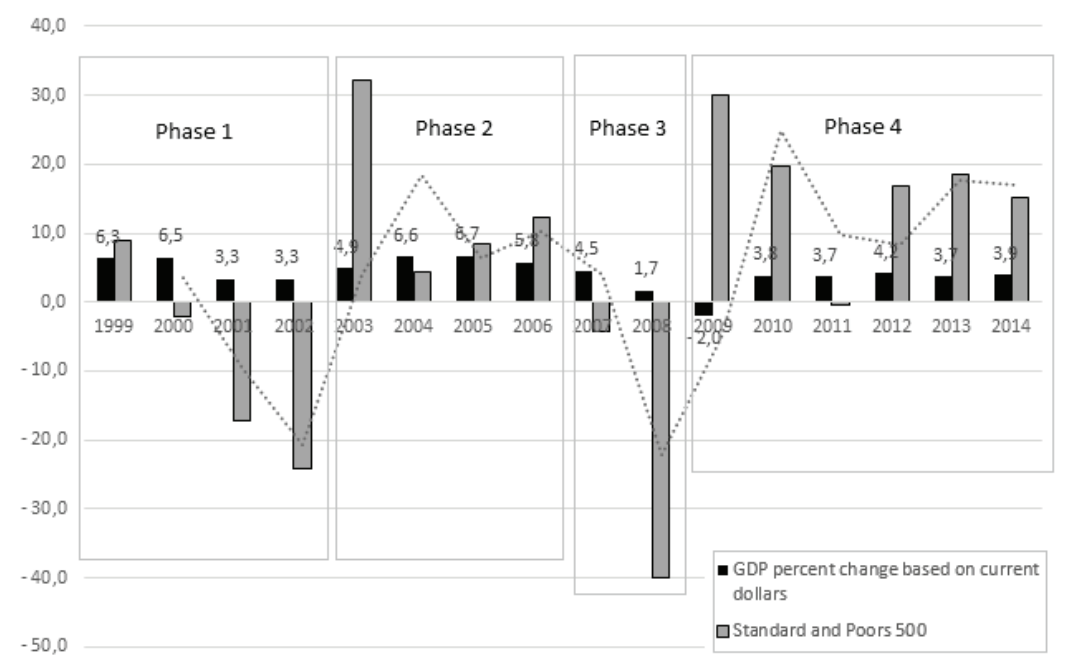

Fig. 3 - US GDP and Standard and Poor's Index \% change in current dollars. Source: own calculations and processing

\section{Test for normality \& parametric/non-parametric methods}

According to time series of financial markets, assumptions related to normality should be taken seriously to obtain reliable conclusions about reality using appropriate statistical procedures (Ghasemi \& Zahedias, 2012). In this research we use the algorithm of Vychytilova (2014) for evaluation correlations between financial market indices that, inter alia, assumes testing normality assumptions visually (histograms, Q-Q plots) and through normality tests (i.e., Shapiro-Wilk test). A generally superior omnibus indicator of non-normality judged over the various symmetric, asymmetric, short- and long-tailed alternatives provides, i.e. Shapiro-Wilk W statistic (Shapiro \& Wilk, 1965; Shapiro, Wilk \& Chen, 1968) that is defined by

$$
W=\frac{R^{4} \widehat{\sigma}^{2}}{C^{2} S^{2}}=\frac{b^{2}}{S^{2}}=\frac{(a \grave{y})^{2}}{S^{2}}=\left(\sum_{i=1}^{n} a_{i} y_{i}\right)^{2} / \sum_{i=1}^{n}\left(y_{i}-\bar{y}\right)^{2},
$$

where

and

$$
\begin{aligned}
& R^{2}=m V^{-1} m, \\
& C^{2}=m V^{-1} V^{-1} m, \\
& a^{\prime}=\left(a_{1}, \ldots, a_{n}\right)=\frac{m V^{-1}}{\left(m V^{-1} V^{-1} m\right)^{\frac{1}{2}}}
\end{aligned}
$$

$$
b=R^{2} \hat{\sigma} / \mathrm{C}
$$

Ghasemi and Zahedias (2012) mentioned that, the Shapiro-Wilk test provides better power than the K-S test and recommended it as the best choice for testing the normality of data. To test the assumption of normality in our research, we use Roysten's (1982) extension of Shapiro-Wilk-W test (Shapiro \& Wilk, 1965) for normality to large samples, available when $2 \leq \mathrm{n} \leq 2000$ (see Royston, 1982) to compute the Shapiro-Wilks statistic and P-Value. 
The small P-value for the Shapiro-Wilk-W test (S-W test) then indicates that the data does not come from a normal distribution and when the smallest P-value amongst the tests performed is less than 0.05 , we can reject the assumption that resistivity comes from a normal distribution with 95\% confidence. Vice versa, when the smallest P-value amongst the tests performed is greater than or equal to 0.05 , we can not reject the idea that the variable comes from a normal distribution with $95 \%$ confidence. Depending on the results of visual inspection about distribution and Shapiro-Wilk test, we use statistical parametric/non-parametric procedures to evaluate correlations between variables.

The strength and the direction of relations between each pair of indices is examined through the: a) parametric Pearson product moment correlation coefficient (2) if benchmarks come from normal distribution; b) or through the nonparametric Spearman's rank correlation coefficient (3) if the indices are not normally distributed; on a scale of -1 to +1 .

,where $\quad x_{i}$ and $y_{i}$ are the values of $x$ and $y$ for the $i^{t h}$ individual.

$$
r=\frac{\sum_{i=1}^{n}\left(x_{i}-x\right)\left(y_{i}-y\right)}{\sqrt{\left[\sum_{i=1}^{n}\left(x_{i}-\bar{x}\right)^{2}\right]\left[\sum_{i=1}^{n}\left(y_{i}-\bar{y}\right)^{2}\right]}}
$$

$$
r_{S}=1-\frac{6 \sum_{i=1}^{n} d_{i}^{2}}{n\left(n^{2}-1\right)}
$$

,where $d_{i}$ is the difference in ranks for $x$ and $y$.

While also taking P-Value into account, we find out whether the indices are significantly correlated. If the P-Value is less than 0.05 we can state that, there is a statistically significant correlation between the pair of indices at the $5 \%$ significance level and vice versa.

\section{RESULTS}

\section{Test for normality}

At first, we present our summary results, whether the variables come from a normal distribution. The estimated parameters of the fitted distribution are shown in Table 1 including the summary results of Shapiro-Wilk test run to determine whether variables (TR/J CRB, TYX, TNX and $V I X)$ can be adequately modeled by a normal distribution with $95 \%$ confidence by comparing the quantiles of the fitted normal distribution to the quantiles of the data. Moreover, we present frequency histograms and Quantile-Quantile plots created to assess visually how well the normal distribution fits (see Fig. 4). 

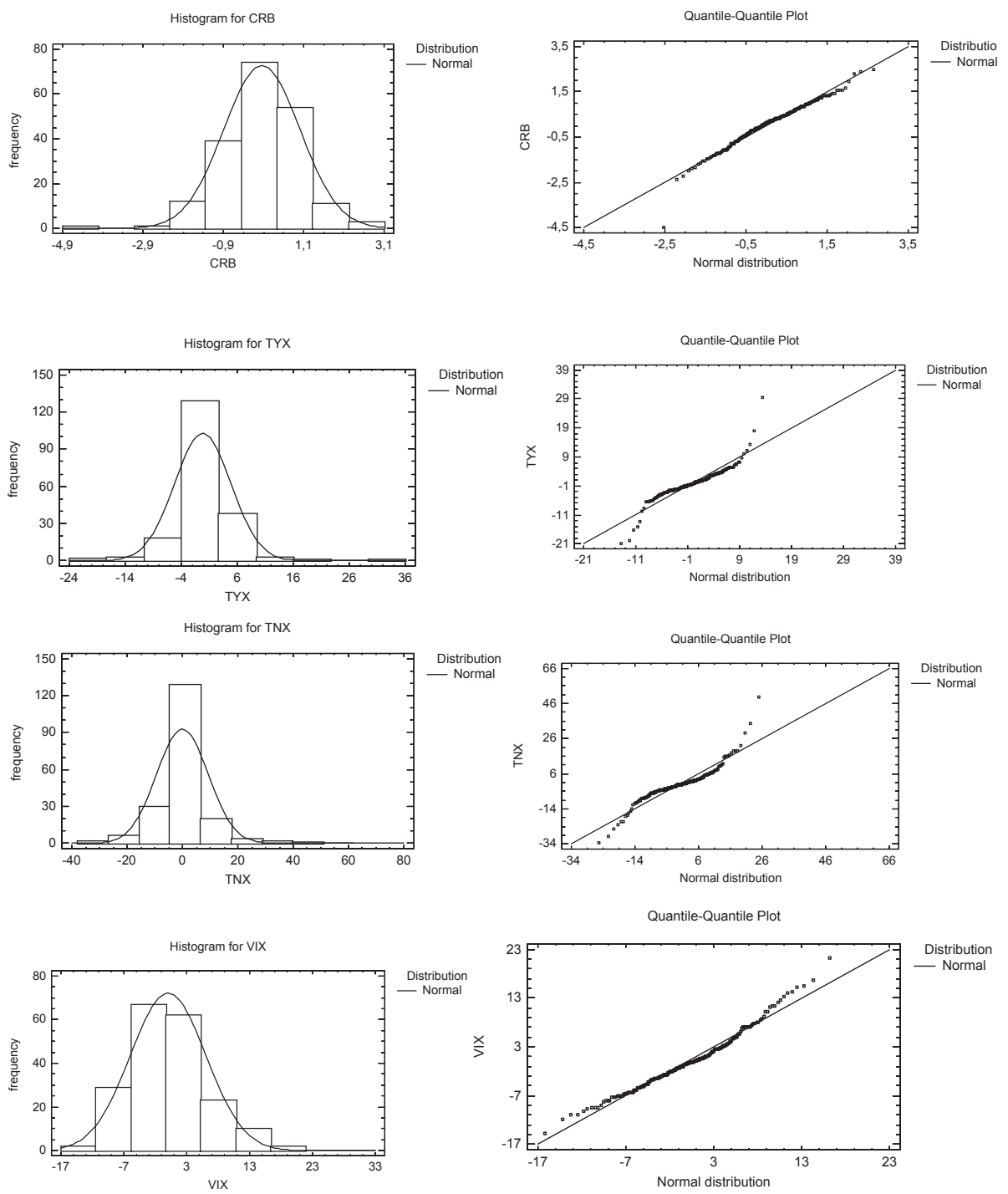

Fig. 4 - Histograms and Q-Q plots of the 1) Thomson Reuters/Jefferies CRB index (TR/J CRB); 2) 30-Year treasury yield index (TYX); 3) 10-Year treasury yield (TNX); and 4) Implied volatility of S\& P 500 index (VIX); over the period 1999-2015/04. Source: Own calculations in Statgraphics Centurion

Tab. 1 - The Shapiro-Wilk test. Source: Own calculations in Statgraphics Centurion.

\begin{tabular}{|c|c|c|c|c|}
\hline $\begin{array}{c}\text { Fitted distribution } \\
\text { Normal }\end{array}$ & Mean & $\begin{array}{c}\text { Standard } \\
\text { deviation }\end{array}$ & S-WW Statistic & P-Value \\
\hline TR/J CRB & 0.0596923 & 0.95411 & 0.978528 & $\mathbf{( 0 . 2 4 4 0 5 6 )}$ \\
\hline
\end{tabular}




\begin{tabular}{|c|c|c|c|c|}
\hline TYX & -0.155846 & 5.05875 & 0.894497 & $(0.0)$ \\
\hline TNX & -0.02928 & 9,32085 & 0.910609 & $(0.0)$ \\
\hline VIX & 0.046 & 6.00846 & 0.971888 & $(0.0400946)$ \\
\hline Conclusion & TR/J CRB & TYX & TNX & VIX \\
\hline $\begin{array}{c}\text { Can we reject the } \\
\text { variable comes from a } \\
\text { normal distribution? }\end{array}$ & $\begin{array}{c}\text { P-Value } \geq 0.05 \\
\text { parametric } \\
\text { methods (1) }\end{array}$ & $\begin{array}{c}\text { P-Value }<0.05 \\
\text { non-param. } \\
\text { methods (2) }\end{array}$ & $\begin{array}{c}\text { P-Value }<0.05 \\
\text { non-param. } \\
\text { methods (2) }\end{array}$ & $\begin{array}{c}\text { P-Value }<0.05 ; \\
\text { non-param. } \\
\text { methods (2) }\end{array}$ \\
\hline
\end{tabular}

Since the smallest P-value amongst the tests performed is greater than or equal to 0.05 , we can not reject the idea that $T R / J C R B$ comes from a normal distribution with $95 \%$ confidence (see, Table 1) On the other hand, since the smallest P-value in the case of TYX, TNX and VIX amongst the tests performed is less than 0.05 , we can reject the idea that TYX, TNX and VIX come from a normal distribution with $95 \%$ confidence (see, Table 1). The visual inspection of Q-Q plots and histograms (see Fig. 4) also support these conclusions.

According to Table 1 and Fig. 4, we will use non-parametric Spearman's rank correlation coefficient (2) that is consequently less sensitive to outliers than the Pearson coefficients to calculate correlations between U.S. treasury bond yields (TYX, TNX) and commodity futures $(T R / J$ $C R B)$, as well as between U.S. treasury bond yields (TYX, TNX) and equity market volatility index (VIX) and compute P-values to test the statistical significance of the estimated correlations.

\section{Correlation matrices}

The Spearman rank correlations between each pair of selected well-known leading market indices are shown in Table 2 (for Phase 1), Table 3 (for Phase 2), Table 4 (for Phase 3 ) and Table 5 (for Phase 4). Table 6 then shows additional summary results for overall last fifteen year period (1999-2015/04).

Tab. 2 - Spearman Rank Correlations in Phase 1 (1999-2002). Source: Own calculations.

\begin{tabular}{|c|c|c|c|c|}
\hline & TR/J CRB & TYX & TNX & VIX \\
\hline TR/J CRB & & -0.1192 & -0.0607 & 0.2009 \\
\hline P-value & & $(0.4190)$ & $(0.6806)$ & $(0.1730)$ \\
\hline TYX & -0.1192 & & 0.8989 & -0.3812 \\
\hline P-value & $(0.4190)$ & & $\mathbf{( 0 . 0 0 0 0 )}$ & $\mathbf{( 0 . 0 0 9 7 )}$ \\
\hline TNX & -0.0607 & 0.8989 & & -0.4441 \\
\hline P-value & $(0.6806)$ & $\mathbf{( 0 . 0 0 0 0 )}$ & & $\mathbf{( 0 . 0 0 2 6 )}$ \\
\hline VIX & 0.2009 & -0.3812 & -0.4441 & \\
\hline P-value & $(0.1730)$ & $\mathbf{( 0 . 0 0 9 7 )}$ & $\mathbf{( 0 . 0 0 2 6 )}$ & \\
\hline
\end{tabular}

According to Table 2, P-values below 0.05 indicating statistically significant non-zero Spearman rank correlations at the $95.0 \%$ confidence level have following pairs of indices: 1) TYX and VIX $(\mathrm{rs}=-0.3812 ; \mathrm{P}$-value $=0.0097) ; 2)$ TNX and VIX (rs= $0.4441 ; \mathrm{P}$-value $=0.0026) ; 3)$ TYX and 
TNX (rs=0.8989; P-value $=0.0000)$. These results indicate that hypothesis H1 about statistically significant positive linkage between U.S. Treasury Bond yields and commodity futures cannot be accepted in Phase 1, while hypothesis $\mathrm{H} 2$ about statistically significant negative linkage between U.S. Treasury Bond yields and equity market volatility is accepted in the Phase 1.

Tab. 3 - Spearman Rank Correlations in Phase 2 (2003-2006). Source: Own calculations.

\begin{tabular}{|c|c|c|c|c|}
\hline & TR/J CRB & TNX & TYX & VIX \\
\hline TR/J CRB & & 0.0314 & 0.1236 & 0.3918 \\
\hline P-value & & $(0.8294)$ & $(0.3969)$ & $\mathbf{( 0 . 0 0 7 2 )}$ \\
\hline TNX & 0.0314 & & 0.9234 & -0.0477 \\
\hline P-value & $(0.8294)$ & & $\mathbf{( 0 . 0 0 0 0 )}$ & $(0.7439)$ \\
\hline TYX & 0.1236 & 0.9234 & & 0.0234 \\
\hline P-value & $(0.3969)$ & $\mathbf{( 0 . 0 0 0 0 )}$ & & $(0.8726)$ \\
\hline VIX & 0.3918 & -0.0477 & 0.0234 & \\
\hline P-value & $\mathbf{( 0 . 0 0 7 2 )}$ & $(0.7439)$ & $(0.8726)$ & \\
\hline
\end{tabular}

According to Table 3, P-values below 0.05 indicating statistically significant non-zero Spearman rank correlations at the $95.0 \%$ confidence level have following pairs of indices: 1) TR/J CRB and VIX (rs=0.3918, P-value $=0.0072) ; 2)$ TYX and TNX ( $r s=0.9234$, P-value $=0.0000)$. These results indicate the hypothesis $\mathrm{H} 1$ nor $\mathrm{H} 2$ cannot be accepted in the Phase 2. However, using non-parametric correlation analysis, we found statistically significant positive correlations between TR/J CRB and VIX.

Tab. 4 - Spearman Rank Correlations in Phase 3 (2007-2008). Source: Own calculations.

\begin{tabular}{|c|c|c|c|c|}
\hline & TR/J CRB & TNX & TYX & VIX \\
\hline TR/J CRB & & -0.0196 & 0.1763 & 0.1972 \\
\hline P-value & & $(0.9252)$ & $(0.3978)$ & $(0.3442)$ \\
\hline TNX & -0.0196 & & 0.9080 & -0.2348 \\
\hline P-value & $(0.9252$ & & $\mathbf{( 0 . 0 0 0 0 )}$ & $(0.2601)$ \\
\hline TYX & 0.1763 & 0.9080 & & -0.2927 \\
\hline P-value & $(0.3978$ & $\mathbf{( 0 . 0 0 0 0 )}$ & & $(0.1603)$ \\
\hline VIX & 0.1972 & -0.2348 & -0.2927 & \\
\hline P-value & $(0.3442$ & $(0.2601)$ & $(0.1603)$ & \\
\hline
\end{tabular}

According to Table 4, P-values below 0.05 indicating statistically significant non-zero Spearman rank correlations at the $95.0 \%$ confidence level have the pair of indices TYX and TNX (rs= 0.9080, P-value $=0.0000)$. These results indicate the hypothesis H1 nor H2 cannot be accepted in the Phase 3. 
Tab. 5 - Spearman Rank Correlations in Phase 4 (2009-2015/04). Source: Own calculations.

\begin{tabular}{|c|c|c|c|c|}
\hline & TR/J CRB & TNX & TYX & VIX \\
\hline TR/J CRB & & 0.1605 & 0.1936 & -0.3104 \\
\hline P-value & & $(0.1645)$ & $(0.0936)$ & $(0.0072)$ \\
\hline TNX & 0.1605 & & 0.9195 & -0.2194 \\
\hline P-value & $(0.1645)$ & & $\mathbf{( 0 . 0 0 0 0 )}$ & $(0.0575)$ \\
\hline TYX & 0.1936 & 0.9195 & & -0.3265 \\
\hline P-value & $(0.0936)$ & $\mathbf{( 0 . 0 0 0 0 )}$ & & $\mathbf{( 0 . 0 0 4 7 )}$ \\
\hline VIX & -0.3104 & -0.2194 & -0.3265 & \\
\hline P-value & $\mathbf{( 0 . 0 0 7 2 )}$ & $(0.0575)$ & $\mathbf{( 0 . 0 0 4 7 )}$ & \\
\hline
\end{tabular}

According to Table 5, P-values below 0.05 indicating statistically significant non-zero Spearman rank correlations at the $95.0 \%$ confidence level have following pairs of indices: 1 ) TR/J CRB and VIX (rs= -0.3104, P-value $=0.0072) ; 2$ TYX and VIX $(\mathrm{rs}=-0.3265$, P-value $=0.0047) ; 3)$ TNX and TYX ( $\mathrm{rs}=0.9195, \mathrm{P}$-value $=0.0000)$. These results indicate that hypothesis H1 about statistically significant positive linkage between U.S. Treasury Bond yields and commodity futures cannot be accepted in the Phase 4, while hypothesis $\mathrm{H} 2$ about statistically significant negative linkage between U.S. Treasury Bond yields and equity market volatility is accepted for the Phase 4. Moreover, using non-parametric correlation analysis, we indicated 4) statistically significant negative correlation between TR/J CRB and VIX.

Tab. 6 - Spearman Rank Correlations for the overall period (1999-2015/04). Source: Own calculations.

\begin{tabular}{|c|c|c|c|c|}
\hline & TR/J CRB & TYX & TNX & VIX \\
\hline TR/J CRB & & 0,1022 & 0,0710 & 0,0171 \\
\hline P-value & & 0,1545 & 0,3229 & 0,8114 \\
\hline TYX & 0,1022 & & 0,9056 & $-0,2545$ \\
\hline P-value & 0,1545 & & $\mathbf{0 , 0 0 0 0}$ & $\mathbf{0 , 0 0 0 4}$ \\
\hline TNX & 0,0710 & 0,9056 & & $-0,1943$ \\
\hline P-value & 0,3229 & $\mathbf{0 , 0 0 0 0}$ & & $\mathbf{0 , 0 0 6 8}$ \\
\hline VIX & 0,0171 & $-0,2545$ & $-0,1943$ & \\
\hline P-value & 0,8114 & $\mathbf{0 , 0 0 0 4}$ & $\mathbf{0 , 0 0 6 8}$ & \\
\hline
\end{tabular}

In addition, the Table 6 shows additional summary results for overall last fifteen year period (1999-2015/04) and indicates non-zero correlations. However, statistically significant correlations at the $95.0 \%$ confidence have following pairs of indices: 1$)$ VIX and TYX ( $r s=-0.2545$, P-value $=0,0004) ; 2$ VIX and TNX (rs = 0.1943, P-value $=0.0068) ; 3)$ TNX and TYX (rs= 0.9056, P-value $=0.0000)$. Correlations between TR/J CRB and TYX or TNX were non-zero, but statistically insignificant. These evidences led us to state that, we can accept hypothesis $\mathrm{H} 2$ about statistically significant negative linkage between U.S. Treasury Bond yields and equity market volatility in overall fifteen year period from January 041999 till April 01 2015, but on the 
other hand, we cannot accept the hypothesis H1 about statistically significant positive linkage between U.S. Treasury Bond yields and commodity futures in overall fifteen year period from January 041999 till April 012015.

Finally, the overall performance relations between investigated U.S. well-known market indicesTR/J CRB, VIX, TYX and TNX during the whole period from January 041999 till April 01 2015, covering all four selected research phases and related to hypotheses H1 - H2, illustrates the Fig. 5. These plots support the previous empirical findings.

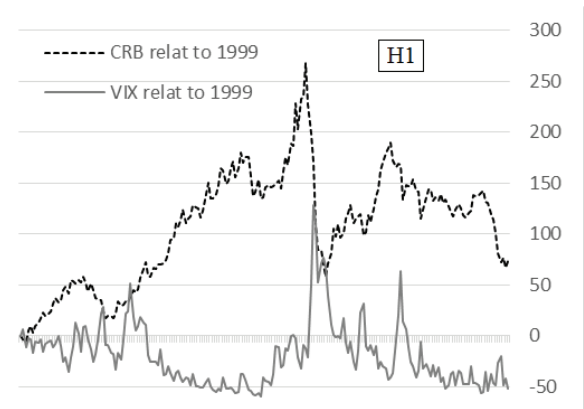

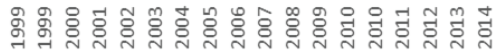

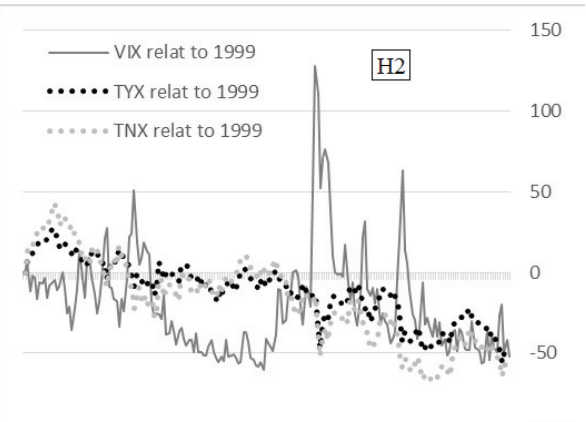

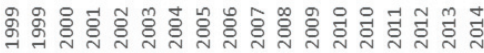

Fig. 5 - Plotted monthly returns (relative to 1999) of selected U.S. leading market indices- TR/J CRB, VIX, TYX and TNX; over the period 04 January 1999 till 01 April 2015 (in \%, 100=1999). Source: Own processing.

\section{DISCUSSION}

Mantegna and Stanley (2000) discussed empirical observations of the temporal correlations detected in time series of price of financial goods and stated, that there were only short-range correlations in price changes, but long-range correlations in the volatility. Further, they discussed empirical analyses often performed with slightly different (i) definitions of the variables investigated, e.g., returns and log price differences, (ii) periods of time analyzed, and (iii) frequency of recorded data; and added results are sensitive to these choices, so particular care must be taken when we compare results obtained by different researchers for different financial goods under different time conditions. Roll (1989) stated that, despite a large number of empirical studies, no one had provided evidence that margin requirements have an impact on volatility and added that, for price limits, there must be a very short-term impact on measured volatility, for the measured market price at a trading halt is likely to understate the direction of movement. Mantegna and Stanley (2000) argued that, however, the complete characterization of the statistical properties of price changes is still lacking, it is plausible that the presence of a relevant degree of crosscorrelation between stocks needs to be taken into account in the modeling of financial markets. This research that has been oriented directly on linkages among the U.S. treasury bond yields, commodity futures and stock market implied volatility returns; showed, inter alia, evidence that such financial assets- bond yields and stock market volatility, moved in the opposite direction 
at the same time (or in other words, that bond yields and VIX diverged) in the past fifteen years, as would be crucial for risk-averting investor using techniques related to the optimal diversified portfolio, while also beneficial for policymakers or corporate financial \& investment department to allocate resources more efficiently, taking stock market cycles and asset-market linkages into account. These findings are, i.e., consistent with previous those of Murphy (2004) or Katsanos (2008). In quite general terms, we therefore, support the a priori idea- financial markets are interconnected. Such knowledge could be beneficial for the building and testing accurate financial market models, and particularly for the understanding and recognizing market cycles.

In addition, general results and conclusion of this research that indicate financial markets financial markets can be interconnected, open new questions and discussion about what all this mean from an economic point of view, what reasons could be behind statistically significant or wear correlations in particular periods, or i.e., what are economic differences in the crisis and noncrisis periods. These areas should be target for the future research.

\section{CONCLUSION}

In this paper we have aimed to examine linkages between monthly U.S. treasury bond yields, commodity futures and equity market implied volatility returns, and to detect statistically significant correlations across selected time periods from January 041999 till April 01 2015. To assess whether these well-known leading market indices come from a normal distribution or not, we have created frequency histograms, Q-Q plots and presented summary results of Shapiro-Wilk test and found that only one variable- Thomson Reuters/Jefferies commodity index (TR/J CRB) can be adequately modeled by a normal distribution. Meanwhile, the smallest P-value of rest of variables amongst the S-W test performed was less than 0.05 , we rejected the idea that U.S. treasury bond yields (TYX or TNX) and VIX come from a normal distribution with $95 \%$ confidence. The strength and the direction of the relation between pair of market indices has been therefore examined within Spearman's rank correlation coefficient and the statistical significance has been tested with P-value statistics. The non-zero correlations between each pair of indices have been estimated, however, the results have not generally been consistent across all sub-periods and the strength of the relations between the pairs of indices has varied in researched years. We have found some evidence of significant negative correlation between the U.S. Treasury bond yields (TYX and TNX) and equity market volatility returns (VIX) over the last fifteen-year period. Moreover, we have also indicated a statistically significant negative linkage between Thomson Reuters/Jefferies commodity index returns (TR/J CRB) and equity market volatility returns (VIX) since 2009, by using non-parametric correlation analysis. These empirical results indicate that financial markets can be interconnected. However, we did not prove the significant linkage between U.S. Treasury bond yields (TYX or TNX) and Thomson Reuters/Jefferies commodity index returns (TR/J CRB) over the last fifteen-year period. This research has been conducted on previous knowledge of foreign empirical studies related to asset-market linkages and contagion, as well as on previous own pre-research, conducted since 2007. Future research should continue to provide deeper investigation, economic reasoning and explanation of relations between the indices in particular phases, and in the crisis and non-crisis periods. 


\section{Acknowledgement}

The authors are thankful to the Operational Programme Education for Competitiveness co-funded by the European Social Fund (ESF) and national budget of the Czech Republic for the grant No. CZ.1.07/2.3.00/20.0147

- "Human Resources Development in the field of Measurement and Management of Companies, Clusters and Regions Performance", which provided financial support for this research.

\section{References}

1. Alaoui, A. O., Dewandaru, G., Azhar Rosly, S., \& Masih, M. (2015). Linkages and comovement between international stock market returns: Case of dow jones islamic dubai financial market index. Journal of International Financial Markets, Institutions and Money, 36, 53 70. doi:10.1016/j.intfin.2014.12.004

2. Bekaert, G., Harvey, C., \& Ng, A. (2005). Market Integration and Contagion. The Journal of Business, 78 (1), 739-69. DOI: 10.1086/426519

3. Black, F., \& Scholes, M. (1973). The Pricing of Options and Corporate Liabilities. Journal of Political Economy, 81 (3), 637-654. doi: 10.1086/260062

4. Chien, M. - S., Lee, C. - C., Hu, T. - C., \& Hu, H. -T. (2015). Dynamic asian stock market convergence: Evidence from dynamic cointegration analysis among china and ASEANEconomic Modelling, 51, 84-98. doi:10.1016/j.econmod.2015.06.024

5. Choi, F. (2003). International finance and accounting handbook (Vol 3.). Hoboken, New Jersey: J. Wiley.

6. Darbar, S. M., \& Deb, P. (1999). Linkages Among Asset Markets in the United States: Tests in a Bivariate GARCH Framework. International Monetary Fund WP, 99(158), 1-25 doi:10.5089 /9781451857566.001

7. Dorodnykh, E. (2014). Determinants of stock exchange integration: Evidence in worldwide perspective. Journal of Economic Studies, 41(2), 292-316. doi:10.1108/JES-08-2012-0111

8. Elton, E., \& Gruber, M. (1995). Modern portfolio theory and investment analysis (Vol 5.). New York: Wiley.

9. Engsted, T., \& Tanggaard, C. (2002). The relation between asset returns and inflation at short and long horizons. Journal of International Financial Markets, Institutions and Money, 12 (2), 101-118. DOI: 10.1016/S1042-4431(01)00052-X

10. Ghasemi, A., \& Zahediasl, S. (2012). Normality Tests for Statistical Analysis: A Guide for Non-Statisticians. International Journal of Endocrinol and Metab., 10 (2), 486-489. doi: 10.5812/ ijem.3505

11. Goetzmann, W., Li, L., \& Rouwenhorst, K. (2005). Long-Term Global Market Correlations. Journal of Business, 78 (1), 1-38. DOI: 10.1086/426518

12. Hong, G., Khil, J., \& Lee, B. (2013). Stock Returns, Housing Returns and Inflation: Is There an Inflation Illusion? Asia-Pacific Journal of Financial Studies, 42 (4), 511-562. DOI: 10.1111/ajfs.12023

13. Katzur, T., \& Sperdijk, L. (2013). Stock returns and inflation risk: economic versus statistical evidence. Applied Financial Economics, 23 (13), 1123-1136. DOI: 10.1080/09603107. 2013.797556 
14. Karolyi, G. (1995). A Multivariate GARCH Model of International Transmissions of Stock Returns and Volatility: The Case of the United States and Canada. Journal of Business \& Economic Statistics, 13, 11-11.

15. Katsanos, M. (2008). Intermarket trading strategies. Chichester, England: Wiley.

16. Lee, B. (2010). Stock returns and inflation revisited: An evaluation of the inflation illusion hypothesis. Journal of Banking \& Finance, 34 (6), 1257-1273. DOI: 10.1016/ j.jbankfin.2009.11.023

17. Levi, M. D. (2005). International finance. (4th ed.). Glasgow: Bell \& Bain.

18. Mantegna, R., \& Stanley, H. (2000). An introduction to econophysics correlations and complexity in finance. Cambridge, UK: Cambridge University Press.

19. Murphy, J. (2004). Intermarket analysis profiting from global market relationships. Hoboken, N.J.: J. Wiley.

20. Ong, M. A. (2015). An information theoretic analysis of stock returns, volatility and trading volumes. Applied Economics. Advance online publication. DOI: 10.1080/00036846.2 015.1019040

21. Pilbeam, K. (2005). Finance and financial markets. (Vol 2.). Hampshire: Palgrave.

22. Roll, R. (1989). Price volatility, international market links, and their implications for regulatory policies. Journal of Financial Services Research, 3 (2-3), 211-246. DOI: 10.1007/ BF00122803

23. Royston, J. P. (1982) An extension of Shapiro and Wilk-W test for normality to large samples. Journal of the Royal Statistical society Series C, 31 (2), 115-124. DOI: 10.2307/2347973

24. Silvennoinen, A., \& Thorp, S. (2013). Financialization, crisis and commodity correlation dynamics. Journal of International Financial Markets, Institutions and Money, 24 (1), 42-65. DOI: 10.1016/j.intfin.2012.11.007

25. Shapiro, S. S., \& Wilk, M. B. (1965). An analysis of variance test for normality (complete samples). Biometrika, 52 (3-4), 591-611. DOI: 10.1093/biomet/52.3-4.591

26. Shapiro, S., Wilk, M., \& Chen, H. (1968). A Comparative Study of Various Tests for Normality. Journal of the American Statistical Association, 63 (324), 1343-1372. DOI:10.1080/016 21459.1968.10480932

27. Spierdijk, L., \& Umar, Z. (2015). Stocks, bonds, T-bills and inflation hedging: From great moderation to great recession. Journal of Economics and Business, 79, 1-37. DOI: 10.1016/ j.jeconbus.2014.12.002

28. Vychytilova, J. (2014). Návrh algoritmu pro hodnocení korelativnosti tržnich indexũ a jeho využití pri kvantifikaci vájemných vazeb mezi tradičnimi trhy podkladových aktiv (Doctoral dissertation). Retrieved from DSpace UTB Dissertations. (Accession Order No. 10563/30831)

29. Xiao, Q., Pan, X., Stephen, M., Yang, Y., Li, X., \& Yang, H. (2015). Discrete scaleinvariance in cross-correlations between time series. Physica A. Statistical Mechanics and Its Applications, 421, 161-170. DOI: 10.1016/j.physa.2014.11.032 
Contact information

Ing. Jana Vychytilová, Ph.D

Tomas Bata University in Zlin, Faculty of Management and Economics

Department of Finance and Accounting

Mostni 5139, 76001 Zlin, Cžech Republic

janka.vychytilova@gmail.com 